\section{Low-pressure fabric hyperbaric chambers}

To the Editor: The Southern African Underwater and Hyperbaric Medical Association (SAUHMA) has released a position statement on low-pressure fabric hyperbaric chambers. ${ }^{[1]}$ The purpose of this statement is to raise awareness about the inappropriate use of lowpressure hyperbaric chambers and potential financial exploitation of members of the public, and it forms part of SAUHMA's strategy to advocate for evidence-based hyperbaric oxygen therapy.

The low-pressure fabric hyperbaric chambers (operating at $<1.4$ atmosphere absolute (ATA)) marketed for sports and alternative medicine have US Food and Drug Administration (FDA) 510(k) clearance for acute mountain sickness only and are designed to be compressed only with air. The FDA prohibits the use of these devices with supplemental oxygen. ${ }^{[2]}$ In South Africa there have been no Medicines Control Council review or cautionary statements, or concerns raised by the Department of Labour, at this stage. SAUHMA has approached the National Department of Health in an attempt to formally regulate hyperbaric oxygen therapy, and in the meantime has taken on the task of self-regulating. A strict hyperbaric facility accreditation system has been set in place to ensure patient safety.

The internationally recognised National Fire Protection Association (NFPA) 101 Life Safety Code and NFPA 99 Health Care Facilities Code describe the requirements for the construction, operation and maintenance of hyperbaric facilities. ${ }^{[3,4]}$

The Pressure Equipment Regulations (through South African National Standard (SANS) 347) classify a typical Gamow bag (based on volume and maximum operating pressure at $<1.5$ ATA) as category 'not regulated. ${ }^{[5]}$ The low-pressure fabric hyperbaric chamber therefore falls outside of any regulated requirements.

The Occupational Health and Safety Act No. 85 of 1993: Diving Regulations $2009,{ }^{[6]}$ promulgated in January 2010, specifies that all persons exposed to pressures in excess of 100 millibar above ambient pressure (1.1 ATA) are required to conform to the requirements of these regulations, unless the treatment concerns medical conditions (non-diving), in which case the facility providing such treatments is required to be accredited by SAUHMA.

SANS 347 Annex A provides a schedule of health and safety standards approved by the Department of Labour. ASME (American Society of Mechanical Engineers) PVHO-1 is listed as an approved safety standard. ${ }^{[7]}$ The ASME PVHO-1 standard applies to any pressure vessel that encloses a human within the pressure boundary, with an external or internal pressure exceeding 2 psig above ambient pressure (1.14 ATA).

SAUHMA's approved indications require that treatment pressures given be at a minimum of 2 ATA. At this pressure, the pressure vessel is categorised as a category III vessel, subject to all the design, construction, testing and certification requirements listed in SANS 347.

Accordingly, SAUHMA requires that all hyperbaric chamber construction is required to satisfy category III requirements, as a minimum, and shall meet the relevant ASME PVHO-1 requirements.
The SANS 347 vessel conformity categorisation 'not regulated' is not appropriate where human occupancy adds a considerable safety responsibility to any pressure vessel product.

As considered by the Undersea and Hyperbaric Medical Society (UHMS), SAUHMA does not endorse the concept of 'in home' therapy at any time. ${ }^{[8]}$

The position statement reaches the following conclusions and makes the following recommendations:

- Hyperbaric oxygen therapy is defined as an intervention in which an individual breathes near 100\% oxygen while [wholly enclosed] inside a hyperbaric chamber at a pressure $\geq 1.4$ ATA.

- SAUHMA-approved indications commence at pressures $\geq 2$ ATA.

- Low-pressure hyperbaric chambers at pressures $\leq 1.4$ ATA are approved for acute mountain sickness only.

- Mild hyperbaric exposures with air deliver no more oxygen to the body than breathing oxygen by mask at sea-level pressure.

- Exposure to treatment pressures $<2.0$ ATA while breathing air does not meet the SAUHMA definition of therapeutic hyperbaric oxygen therapy and does not achieve the minimum pressure and oxygen levels required for any SAUHMA-approved indication.

- All SAUHMA-approved indications require that the patient breathe near $100 \%$ oxygen while enclosed in a chamber pressurised to a minimum of 2 ATA.

- SAUHMA does not recommend the use of mild hyperbaric therapy for any medical purpose other than acute mountain sickness.

This position statement is but one example of SAUHMA's efforts to maintain co-operation between itself and other medical and scientific bodies and organisations, the objectives of which are wholly focused on advancing evidence-based medicine.

This letter has been reviewed and approved by the SAUHMA Executive Committee.

\section{F Burman, SAUHMA Technical Advisor}

Midrand, Gauteng

fburman@dan.org

1. Southern African Underwater and Hyperbaric Medical Association. SAUHMA Position Statement Low-pressure fabric hyperbaric chambers. http://sauhma.org/sauhma-position-statement (accessed 26 February 2019).

2. US Food and Drug Administration. CFR - Code of Federal Regulations Title 21. https://www.accessdata. fda.gov/scripts/cdrh/cfdocs/cfffr/cfrsearch.cfm (accessed 26 February 2019).

3. National Fire Protection Association. NFPA 101: Life Safety Code. 2015 edition. Quincy, Mass.: NFPA, 2015 4. National Fire Protection Association. NFPA 99: Health Care Facilities. Quincy, Mass.: NFPA, 2018.

5. South African National Standard. SANS 347: Categorization and Conformity Assessment Criteria for all Pressure Equipment. 2nd ed. Pretoria: South African Bureau of Standards, 2012.

6. South Africa. Occupational Health and Safety Act No. 85 of 1993. Diving Regulations 2009 . Government Gazette No. 32907, January 2010. Published under Government Notice R41. https://www. labourguide.co.za/healthsafety/787-diving-regulations-2010/file (accessed 12 March 2019).

7. American Society of Mechanical Engineers. Safety Standard for Pressure Vessels for Human Occupancy ANS/ASME PVHO-1-1912 New York: ASME 2016.

8. Undersea and Hyperbaric Medical Society. UHMS Position Statement: Conduct of hyperbaric oxygen Undersea and Hyperbaric Medical Society. UHMS Position Statement: Conduct of hyperbaric oxygen
therapy at sites other than clinical hyperbaric treatment facilities. https://www.uhms.org/images therapy at sites other than clinical hyperbaric treatment facilities. https://www.uhm
Position-Statements/uhms in-home_position_statem.pdf (accessed 26 February 2019). 